\title{
APPLICATION OF X-MP RADAR FOR DEBRIS FLOW DISASTER MITIGATION IN MERAPI VOLCANIC RIVERS INDONESIA
}

\author{
Ratih Indri Hapsari ${ }^{1, *}$, Satoru Oishi ${ }^{2}$ and Rosa Andrie Asmara ${ }^{3}$ \\ ${ }^{1}$ Department of Civil Engineering, State Polytechnic of Malang \\ Jl. Soekarno-Hatta 9, Malang 654141, Indonesia \\ ${ }^{2}$ Research Center for Urban Safety and Security, Kobe University, Japan \\ 1-1 Rokko-dai, Nada-ku, Kobe 657-8501, Japan \\ ${ }^{3}$ Department of Informatics Engineering, State Polytechnic of Malang \\ Jl. Soekarno-Hatta 9, Malang 654141, Indonesia \\ 1*ratihindri@gmail.com, ${ }^{2}$ tetsu@phoenix.kobe-u.ac.jp, \\ rosa.andrie@polinema.ac.id
}

\begin{abstract}
Volcanic debris flow disaster is highly triggered by rainfall. However, limited access to the area of active volcano slope and damage of the observation station restricts the direct measurement by rain gauges. High-resolution $X$-band weather radars have been extensively used in hydrological researches and flood mitigation programs. In this study, the potential utilization of $\mathrm{X}$-band multi-parameter compact (X-MP) radar for volcanic disaster mitigation is in real-time is presented. The study area is the rivers on Mount Merapi, which is historically the most active volcano in Indonesia. In the first part, the use of X-MP radar in real-time scheme is described. This part demonstrates the radar-rainfall estimation and the first attempt to predict the rain echo motion in short-term by using extrapolation model. In the second part, the advantage of radar for showing the spatially predominant rainfall for vulnerability assessment is demonstrated. The susceptibility level of three river basins, Pabelan River, Boyong River, and Gendol River, is generated using radarrainfall spatial distribution intensive observation period between October 2015 and February 2016. The real-time analysis has shown the advantage of radar to observe short-localized rainfall event. The results of radar extrapolation model suggest the consideration of uncertainties in the prediction system. The susceptibility score calculated from frequency of rainfall threshold exceedance and slope calculated by parametric modeling technique can be used to determine the susceptible area. The analysis finds that generally Boyong River is the most prone area for lahar flow, particularly at the region within $2 \mathrm{~km}$ to $3 \mathrm{~km}$ from the summit. The proposed X-MP radar utilization would be useful for mitigation of multimodal sediment disaster caused by volcanic eruption.
\end{abstract}

Keywords - X-MP radar; Merapi; Debris flow; Rain prediction; Thresholds susceptibility

* Corresponding Author 


\section{INTRODUCTION}

Volcanic eruptions cause many direct and indirect hazards. Debris flow has been recognized as among the worst indirect hazards of volcanic ejection disaster. Thousands of people in the world have been affected by rapidly flowing mixture of rock debris and water from a volcano and their deposit, with solid fractions greater than that of normal streamflow, which is known as lahar [1]. Lahar flow of Mount Pinatubo Philippine in 1991 has killed 1500 people within 2 years. In 2010, Mount Merapi Indonesia ejection have also caused the severe impact on people, livelihood, and properties. High rainfall with long duration is highly associated with lahar flow [2]. Therefore, estimation of rain event characteristic in short duration and scale is indispensable for mitigating volcanic disaster. Limited access to the area of active volcano slope as well as risk of measurement gages damage due to disaster lead to the difficulty of observing the rainfall in the high elevation of a catchment. Weather radars are appealing instruments for observing rainfall over large spatial domains within fine time resolutions. Unlike single-polarization radar, multi-parameter radar has ability to observe rain with high accuracy. X-band multi-parameter (X-MP) radar observation, whereby $0.5 \mathrm{~km}$ resolution can be achieved every 2 minutes, provides more detail rainfall information than conventional radars. Recent studies confirmed the significance of the rainfall spatial structure in flood runoff generation [3]. Merapi volcano is historically the most active volcano in Indonesia. The significant eruption events were in year of 1872, 1953, 2006, and 2010. Rivers on this mountain flank are vulnerable from lahar. The adverse impacts tend to be more critical as most rivers pass through highly populated region of Yogyakarta Special Province. In October 2010, lahar disaster at Gendol River has reached $20 \mathrm{~km}$ and buried 21 houses. Since 2015, X-MP radar is installed in Mount Merapi. Compared to the the number of available rain gauges in this area, the radar has wider coverage with high resolution. Lahar floods are distinguished from other event types by the small time and spatial scales. With short lead times, short-term prediction is required for the forecasting rain-induced debris flow. There have been some past researches on Merapi lahar flow [1,2]. However, none of them studied the susceptibility analysis of lahar by using radar for disaster mitigation.

Therefore, this paper presents the use of the high-resolution X-MP radar for rainfall estimation and prediction triggering the debris flow in Merapi volcanic region, Yogyakarta, Indonesia. In summary, the contributions of this study are summarized as follow:

a. We evaluate the capability of X-MP radar for estimating and forecasting the rainfall in Merapi volcanic rivers and to develop the susceptibility assessment system by using X-MP radar.

b. We use radar in the real time scheme by applying radar echo extrapolation techniques, which have been the mainstream of rainfall forecasting until recently [4].

c. We analyze the historical data from intensive observation period spatially to obtain the susceptibility level of three volcanic rivers to the debris flow based on the rainfall parameters thresholds along with slope gradient.

d. We propose a system which is contribute to the development of decision support system for debris disaster response by using X-MP radar.

The rest of this paper is organized as follow: Section 2 presents the data used and the proposed method. Section 3 presents obtained results and following by discussion. Finally, Section 4 concludes this work. 


\section{MATERIAL AND PROPOSED METHOD}

This section presents the data used and the proposed method.

\subsection{STUDY AREA AND X-MP RADAR}

The study is conducted in river basins originated from Merapi volcano, Yogyakarta Special Province, Indonesia $\left(7.5407^{\circ} \mathrm{S}, 110.4457^{\circ} \mathrm{E}\right)$ with elevation of 3317 AMSL as depicted in Figure 1.

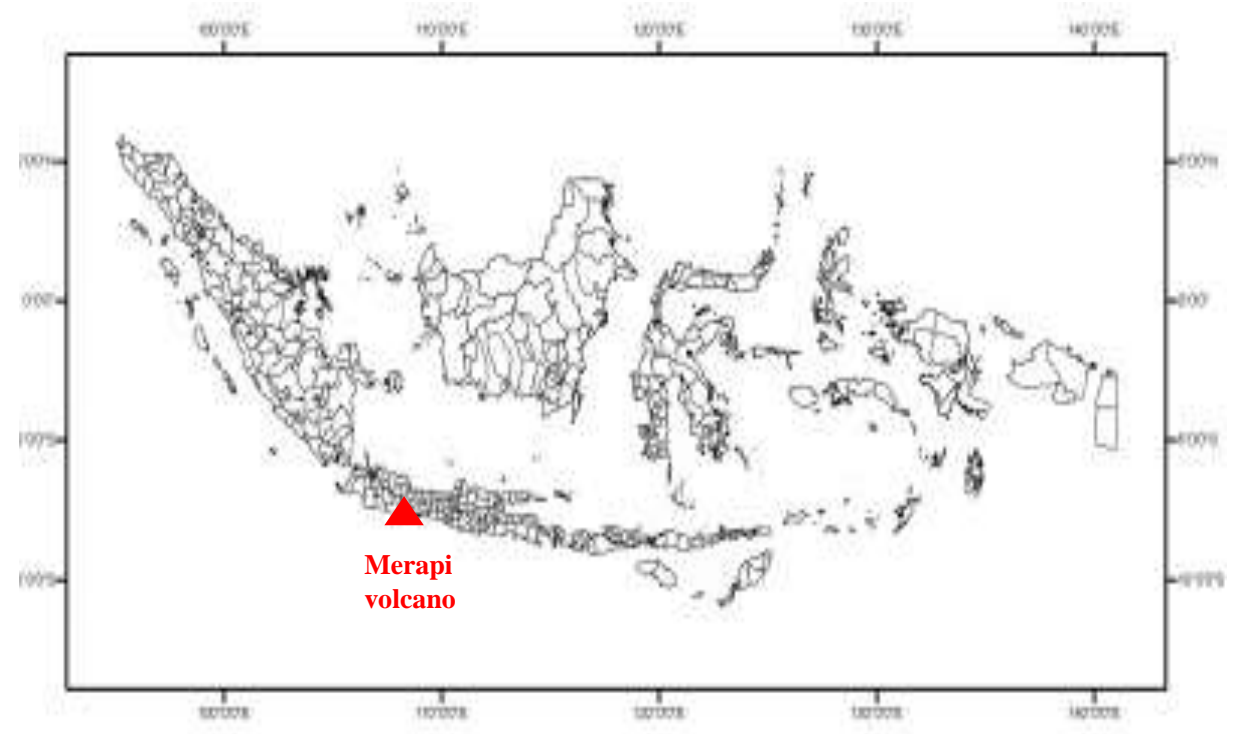

Fig. 1 Study Area

There are 12 rivers which are vulnerable for lahar, e.g. Pabelan River, Boyong River, Putih River, Kuning River, Gendol River, Krasak River as depicted in Figure 2. As many as 70,000 people are living in the first danger zone over the Merapi flank. Boyong River is the river that passes through Yogyakarta urban area.

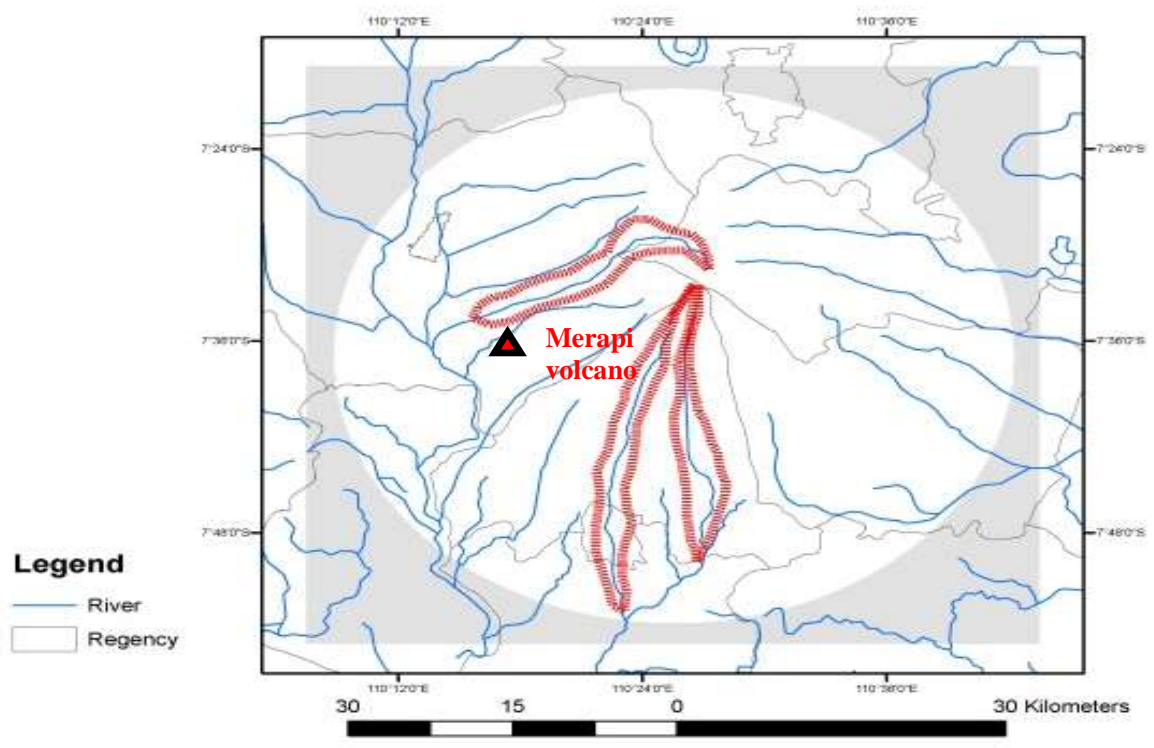

Fig. 212 rivers which are vulnerable for Merapi's lava 
Merapi eruption in October 2010 has caused lahar flow in the subsequent rainy season. High amount of rain in March 2011 has brought $60 \%$ of volcanic which was accumulated on the top. The past-recorded event of lahar flow was as far as $20 \mathrm{~km}$ with $110 \mathrm{~km} / \mathrm{hr}$ speed of flow. This disaster led to the high sedimentation of the rivers. In Gendol River, sediment reached $20 \mathrm{~km}$ and buried 21 houses, which evacuated 200 residents.

In this study, Boyong River, Gendol River, and Pabelan River are selected as case study. Catchment origin is important aspect in evaluating lahar flow as the flow typically occurs along the river stream. Delineation of these three rivers are conducted by extraction from topographical map from ASTER GDEM with $30 \mathrm{~m}$ resolution (See Figure 3).

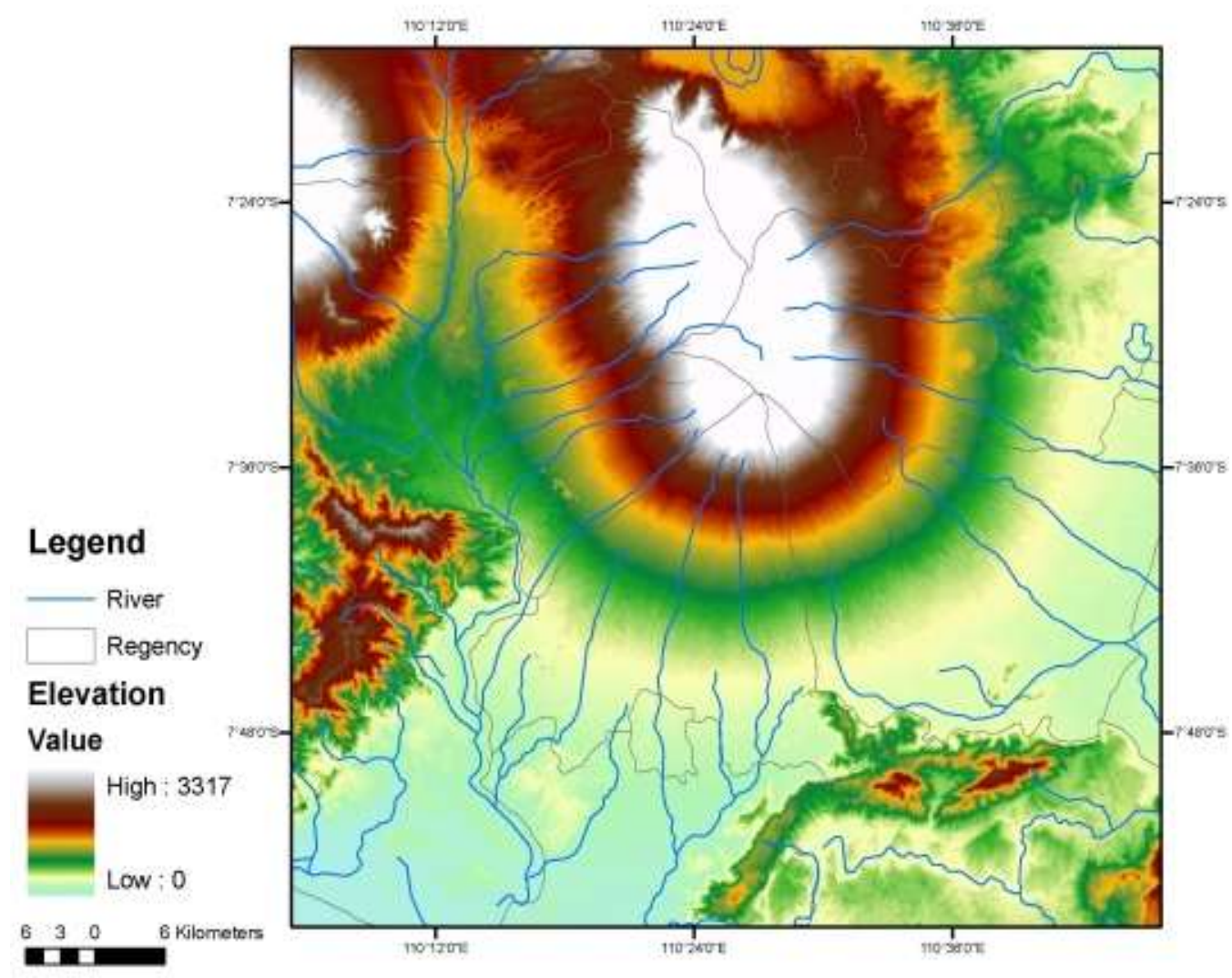

Fig. 3 Topography map

In January 2015, X-MP radar was installed in Merapi Museum with the elevation of 755 MSL as shown in Figure 4. The purpose of installing this radar is to provide high precision monitoring and forecasting of short local meteorological phenomenon to contribute to better society safety from meteorological disasters, which includes vertical structure of cumulonimbus, nimbus movement, raindrops, multi-directional rain intensity, rain echo motion, and even volcanic ash. This radar provides rainfall measurement with $0.5 \mathrm{~km}$ spatial resolution and 2 minutes temporal resolution. Rainfall intensity (mm/hour) in 500 amsl CAPPI scan during the intensive observation period during October 2015 and February 2016 are used in this study. The initial assessment of radar-rainfall has shown the conformity of the rainfall intensity obtained from X-MP radar and rain gauge indicating the reliability of radar observation. 


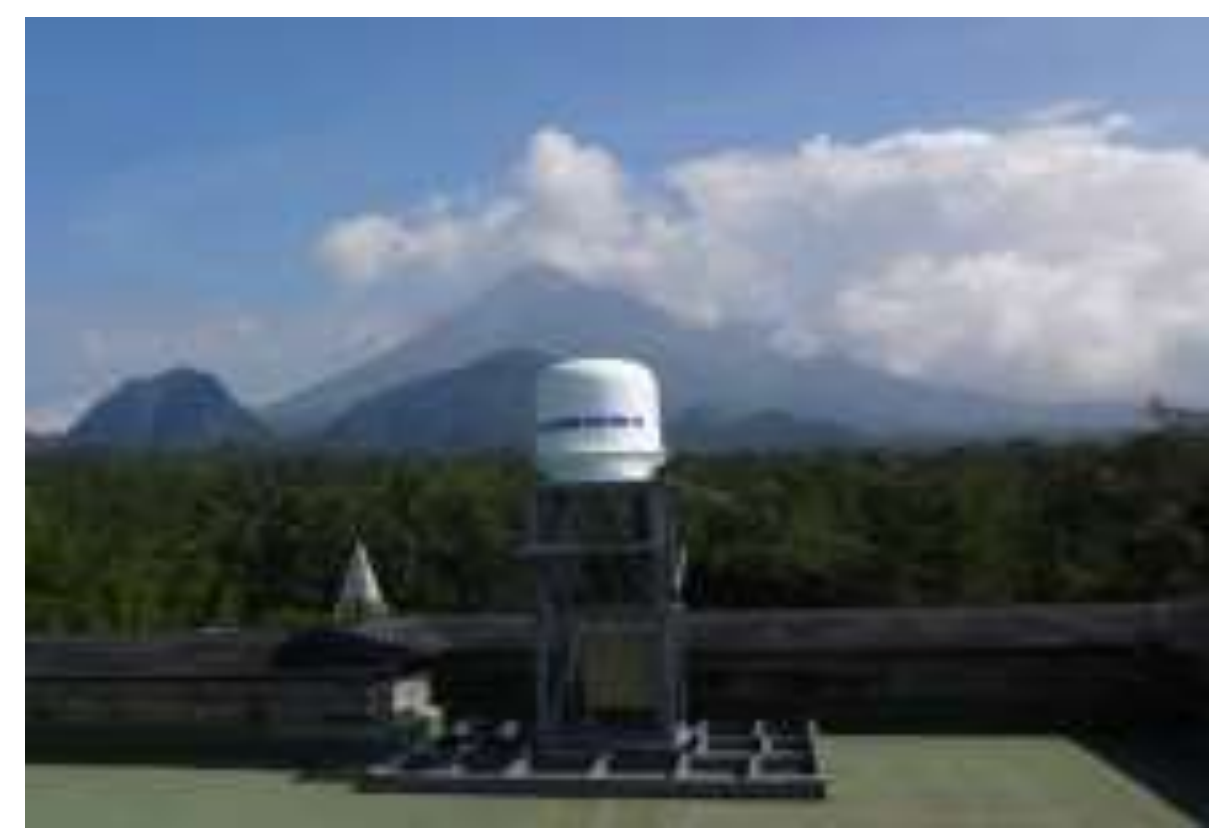

Fig. 4 Radar range

\subsection{RADAR ECHO EXTRAPOLATION MODEL}

The rainfall short-term prediction used in this study for real-time prime prediction is radar echo extrapolation model proposed by Shiiba, et al. in [5]. The dynamic of the horizontal rainfall intensity distribution $r(x, y, t)$ with the spatial coordinate $(x, y)$ at time $\mathrm{t}$ is described as follows:

$$
\begin{gathered}
\frac{\partial r}{\partial t}+m \frac{\partial r}{\partial x}+n \frac{\partial r}{\partial y}=w \\
m=\frac{d x}{d t}, n=\frac{d y}{d t}, w=\frac{d z}{d t}
\end{gathered}
$$

where, $\mathrm{m}$ and $\mathrm{n}$ are advection vector by which the horizontal rainfall distribution is assumed to be translated, and $\mathrm{w}$ is the growth/decay rate of rainfall intensity. The $\mathrm{m}, \mathrm{n}$, and $\mathrm{w}$ formations are specified on each grid linearly in the manner of:

$$
\begin{aligned}
& m(x, y)=c_{1} x+c_{2} y+c_{3} \\
& n(x, y)=c_{4} x+c_{5} y+c_{6} \\
& w(x, y)=c_{7} x+c_{8} y+c_{9}
\end{aligned}
$$

The $c_{1}$ to $c_{9}$ parameters are optimized by linear least square using past observed radarrainfall. This model is powerful for predicting short events within 3 hours lead time, yet the performance decreases rapidly for longer prediction time. Here, the predictability is verified by comparing the predicted and observed rainfall. During the observation period, there was at least three recorded event of debris attack, i.e., December 7, 2015, December 18 2015, and February 17, 2016. In this paper, the last event that occurred in Pabelan River is simulated by using extrapolation model.

\subsection{LAHAR SUSCEPTIBILITY ANALYSIS}

Susceptibility is the feature of people or properties that can be potentially influenced by natural phenomenon. As mentioned by Westen and Daag in [6], lahar activities are highly 
affected by rain intensity and rain duration. The initiation of lahar tends to follow nonlinear relation of rain intensity and duration. Rodolfo and Arguden in [7] showed empirical relationship of rainfall duration (D) and intensity (I) $\mathrm{I}=27.3 \mathrm{D}^{-0.38}$ as lahar flow initiation threshold. The criteria of lahar initiation are duration of more than 1.4 hours, water volume of more than $40 \mathrm{~mm}$, rain intensity of more than $11 \mathrm{~mm} / \mathrm{hr}$, and the existence of number of rain events of $10 \mathrm{~mm}$ within $10 \mathrm{~min}$ [7].

Islam and Sado in [9] used frequency analysis of the flood impact to distinguish area with high and low flood risk. The schematic is shown in Figure 5. From many recorded data, the area without flood is marked with 8 . Area with 1 time flood are marked as 5, 6, and 7. Finally, the most frequent flooded area is marked with one. This method is employed to identify area with high likelihood of rainfall. The prevalence is shown by probability map developed based on data series during the observation campaign period.
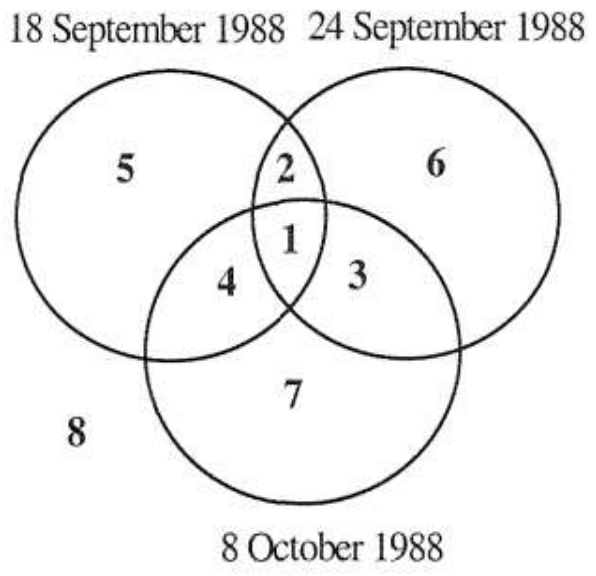

Fig. 5 Schematic of rainfall frequency concept [9]

Many physical models of lahar transport as well as vulnerability zoning model, such as Titan2D [9] and Kanako in [10] include topography as an important contributing factor to debris flow prediction. Therefore, surface steepness is included as an indicator of lahar flow vulnerability. The slope factor is generated by GIS technique using $30 \mathrm{~km}$ GDEM data.

This study uses parametric approach introduced by Niu, et al. in [11], who adopted the DRASTIC Model developed by United States Environmental Protection Agency. In this model, an index of vulnerability score is calculated using a weighted sum of some indicators:

$$
\text { Susceptibility score }=\text { Rank }_{\text {rain }} \text { Weight } t_{\text {rain }}+\text { Rank }_{\text {slope }} \text { Weight } t_{\text {slope }}
$$

In this research, the weights are assigned the same for both rain and slope parameters. The spatially distributed score is calculated by GIS technique. The vulnerability index is calculated for each grid with the same resolution as radar.

\section{RESULTS AND DISCUSSION}

This section presents obtained results and following by discussion.

\subsection{RAINFALL ESTIMATION BY X-MP RADAR}

Figure 6 below shows the observation results of X-MP radar on February 17, 2016 case. 


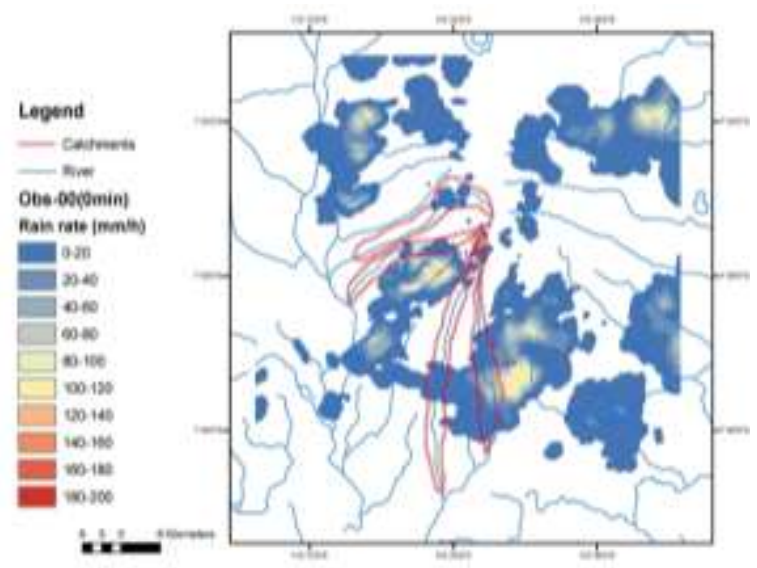

Fig. 6 Observed spatial radar-rainfall intensity of February 17, 2016 case at 15.00 JST

From Figure 6, the rainfall spatial distribution indicates that the rainfall as high as 70 $\mathrm{mm} / \mathrm{hr}$ was detected in the upstream and downstream of the Gendol rivers between 16.30 LST to 17.00 LST. From the hyetograph, it can be seen in Figure 7 that the grid point rainfall intensity ranged from $1 \mathrm{~mm} / \mathrm{hr}$ to $90 \mathrm{~mm} / \mathrm{hr}$. From Figure 7, in average, the rain over Gendol basin increased at 15.00 LST and reached the maximum at 16.15 LST with 3 hours total duration of heavy rain events. This type of rain event highly contributed to the occurrence of the debris disaster along the river stream. As formulated by MLIT in [12] a rain event that has quite high intensity within the event and there was not rainfall in 24 hours before is attributable to the sediment flow disaster.

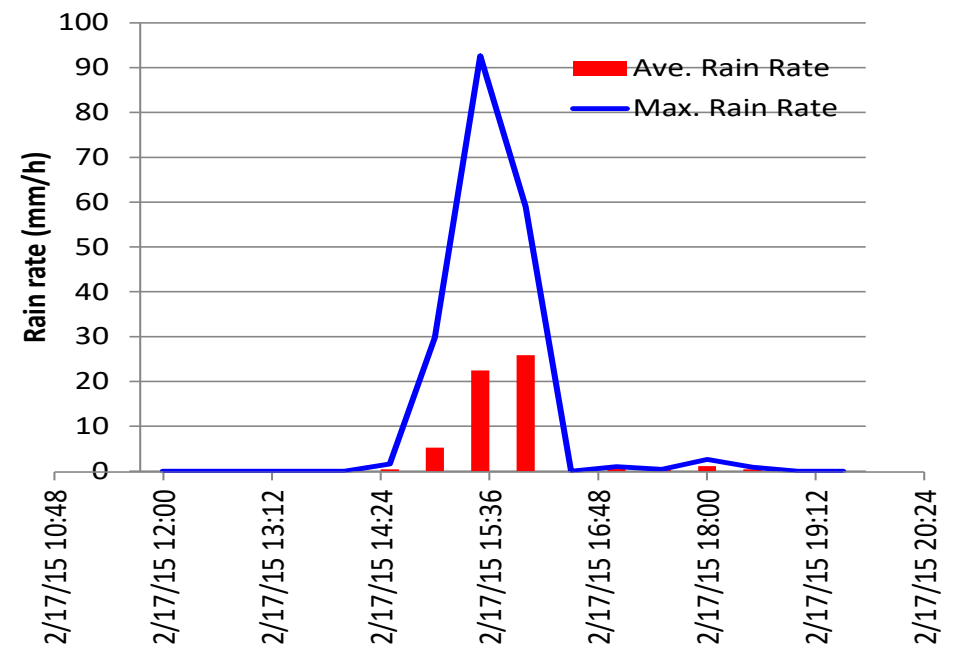

Fig. 7 The hyetograph of rainfall spatial average on February 17, 2016

Rainfall spatial average observed by X-MP illustrated in Figure 3 left indicates that the radar could capture the rainfall characteristic difference in terms of the magnitude as well as timing. Though Gendol River and Boyong River are near, the rainfall intensity of Gendol River on that day was much higher than that of Boyong River. For other cases, it can be seen that peak rain occurred with comparable amount but with short delay between one basin and another basins. It indicates that the radar could observe well the movement of the rain echo. As studied by Maki, et al. [13] X-band radar observation provides more detail rainfall information compared to rain gauges network, even with conventional radars. This research suggests that providing severe rainfall information at small scales with X-MP 
radar is essential for lahar disaster prediction, as the catchment of river basins on the volcanoes flanks is generally small.

\subsection{REAL-TIME SHORT-TERM PREDICTION OF RAINFALL}

Figure 8 below demonstrates the images obtained from rainfall short-term prediction. The rainfall in the whole radar domain at 14.30 LST and three layers back are introduced to the extrapolation model to predict the rain with lead-time of 3 hours in the future. As the event duration of Gendol disaster was 3 hours, this model is expected to have benefit for predicting the timing of rain-induced lahar prediction. The right panel of Figure 8 provides the observation of radar to evaluate the performance of the prediction model for 1 hour lead time. The qualitative instant skill assessment through visual comparison found that on some occasions the rain echo are in the incorrect position.
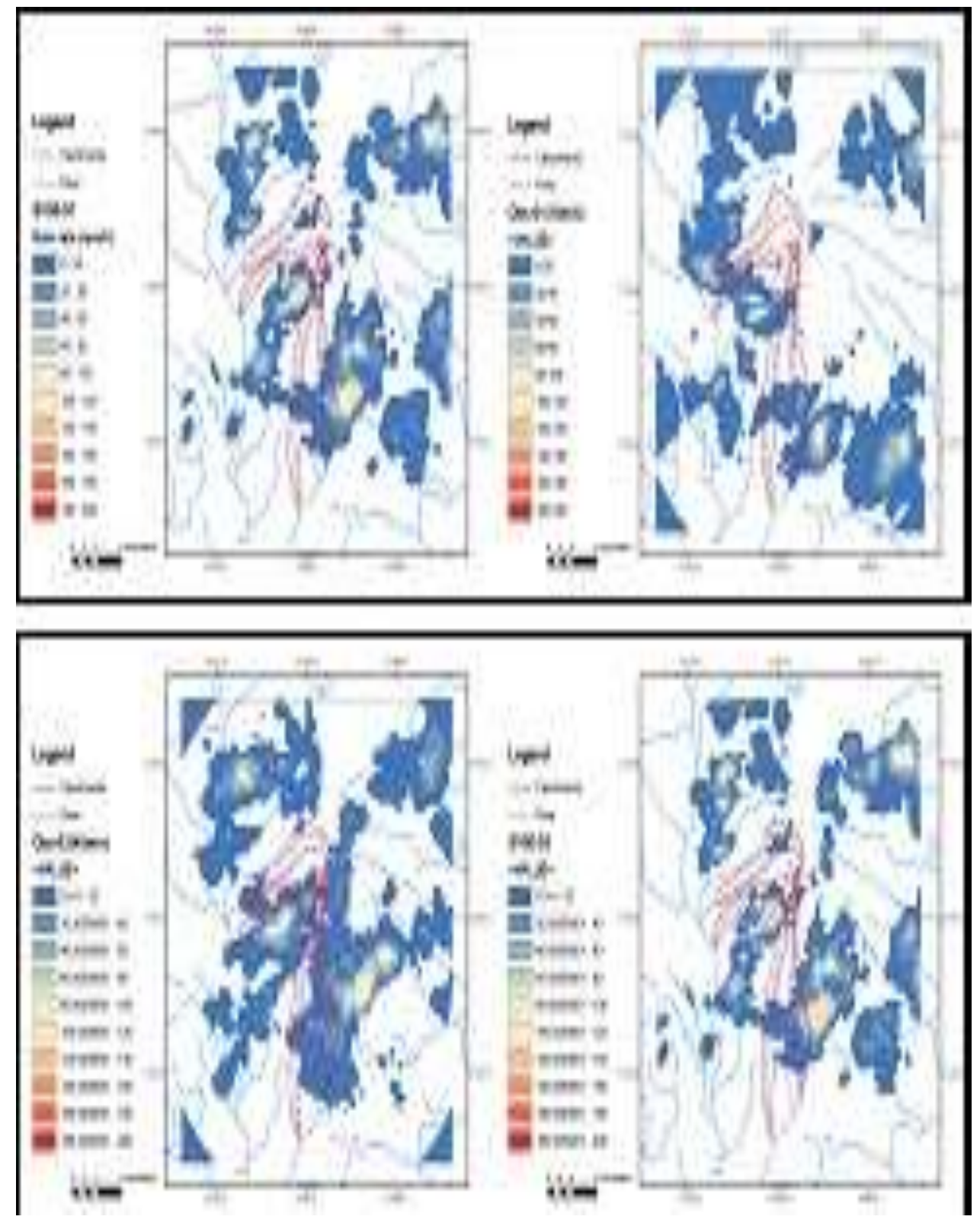

Fig. 8 Results of rainfall prediction of Gendol River disaster case 

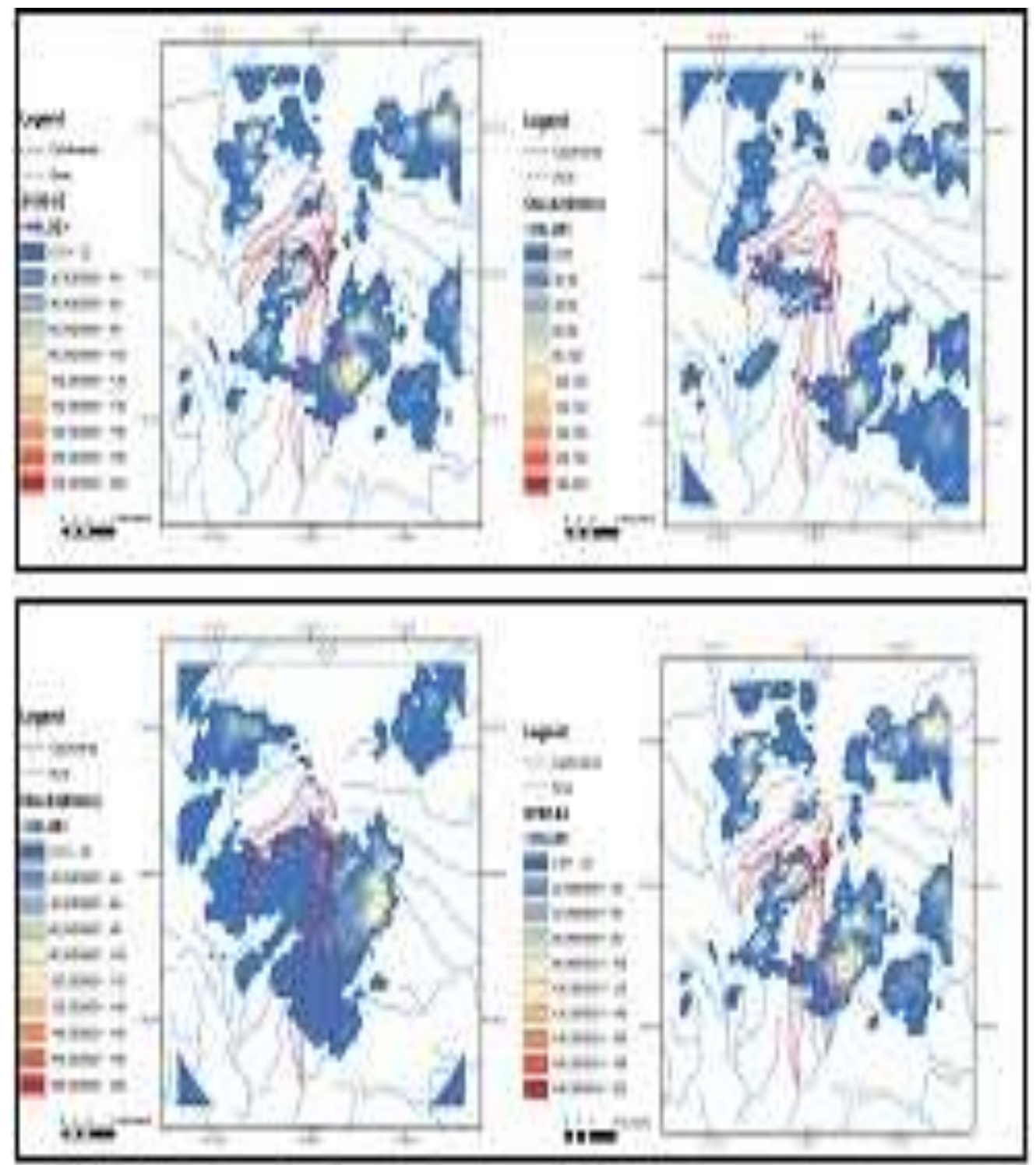

Fig. 8 Results of rainfall prediction of Gendol River disaster case (Cont.)

In Figure 9, the rainfall observation and prediction are compared in time-intensity variation chart. This simulation finds that in some cases, the rainfall magnitude the prediction in a longer term provides decreasing performance. According to Reyniers in [4], despite variety schemes have been included to improve the extrapolation models, there is still a limit of prediction accuracy. Yet, radar-echo extrapolation model has been the mainstream of rainfall short-term prediction until recently [4,14]. Morevoer, the volcanoes river basin is characterized by its short localized raindall within the narrow catchment. In order to overcome this limitation, conducting uncertainty analysis for the uncertainty is needed for future improvement. 


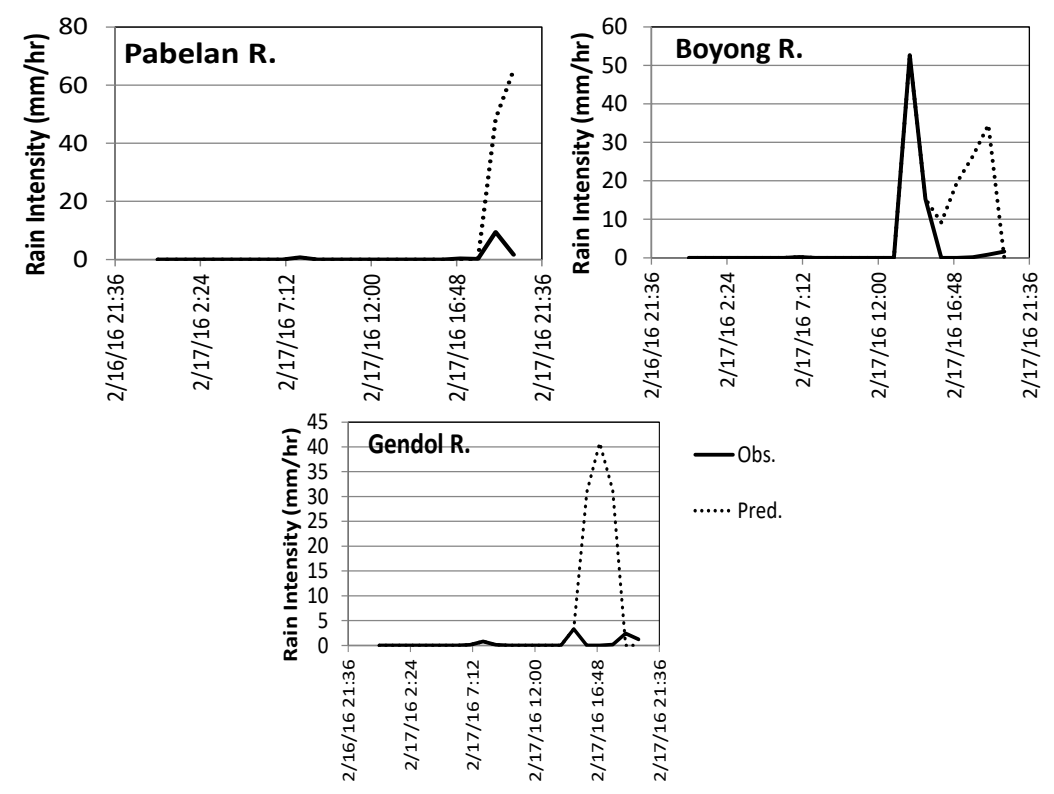

Fig. 9 Observed spatial radar-rainfall intensity and hyetograph of rainfall spatial average on February 17, 2016 case at 15.00 JST

\subsection{VULNERABILITY \\ ASSESSMENT BASED ON \\ HISTORICAL PREDOMINANT RAIN}

\subsubsection{RAIN AFFECTED PROBABILITY}

The results of prevailing rainfall more than threshold of $11 \mathrm{~mm} / \mathrm{hr}$ calculated by rain probability is illustrated in the left side of Figure 10. These values are calculated from all rainfall measurement data during the intensive observation period. The probability spans from above $0 \%$ to nearly $100 \%$. The number of heavy rain events with duration of more than 1.4 hours is show in the right side of Figure 10. Some areas have high probability of rainfall, such as around the summit of Merapi and above Progo River Magelang. This phenomenon may be attributable to orographic effect. Few regions experience two times of heavy rains that may induce debris flow and many places have one time heavy rain during October 2015 to February 2016.

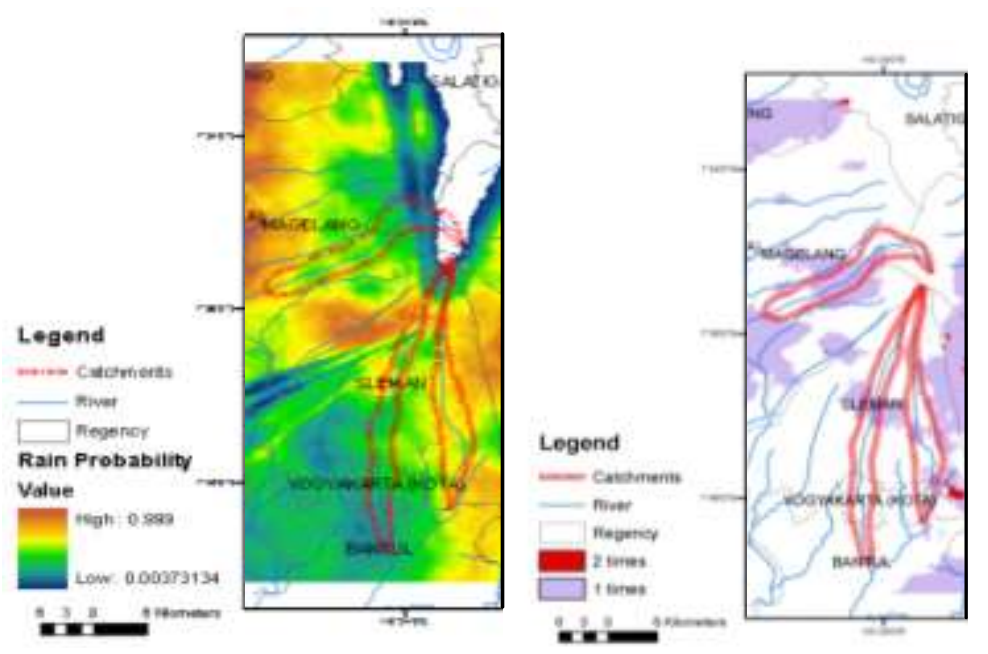

Fig. 10 Rainfall factors retrieved from observation campaign period data 


\subsubsection{SLOPE FACTOR}

From GDEM topographical data, slope of the terrain is calculated. The value is converted to absolute value as depicted in Figure 11. From the Figure 11, it can be inferred that $2 \mathrm{~km}$ surrounding the summit have the highest slope factor. This value will be combined with rain frequency factor to analyze the lahar susceptibility in each region.

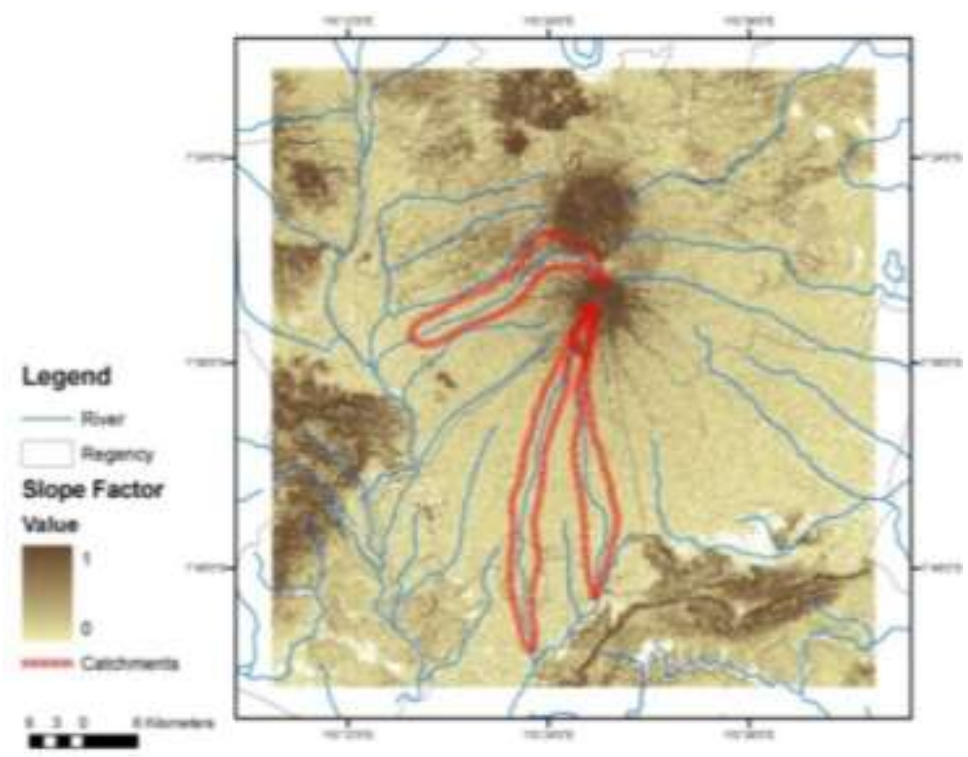

Fig. 11 Slope factor of Mount Merapi

Based on the probability of rain events selected from the lahar threshold and slope factors, the susceptibility score is calculated spatially for each calculation grid by parametric method. Figure 12 provides the susceptibility of the catchments to the debris flow disaster drawn from data of observation campaign period.

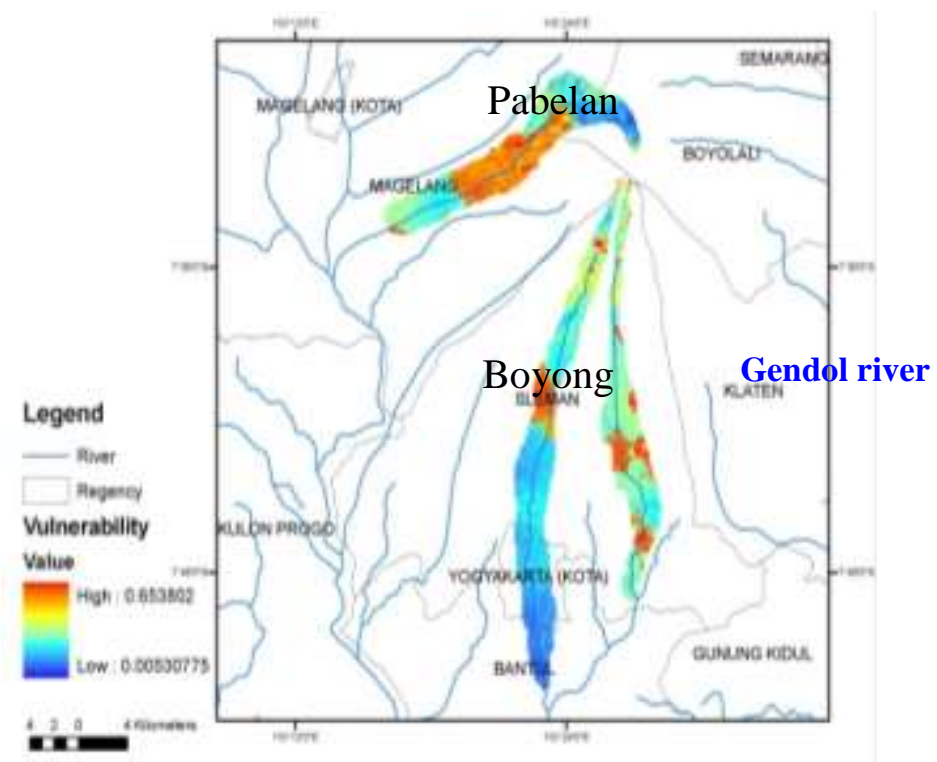

Fig. 12 Susceptibility of the catchments to the debris disaster from all observation data

Red, yellow, and blue colors indicate the high, medium, and low susceptibility respectively. The past lahar flood cases on December 7, 2015, December 18, 2015, February, 17, 2016, and October, 27, 2016 have been reported that the lahar flood occurred 
mostly Gendol Rivers. In addition, based on the disaster-prone mapping assessment by Geological Agency of Indonesia, Gendol River is included in the highest vulnerability level with wide range of prone area. The finding of the research is corroborated by the past observation, where Gendol River has middle to high vulnerability all over the catchment indicated by yellow-red color, particularly in 2 to $3 \mathrm{~km}$ from the top. Though Pabelan River shows larger red region, the location is somewhat lower from the top.

The prime motivation for communicating the forecast information like the abovementioned scheme is to assist better decision making on the part of those receiving the information (Gill, 2008). By using the vulnerability map based on historical predominant rain as shown previously, the detail information of the prone regions can be shown. The precipitation falls over certain small area can be distringuished with the neighboring area even in $100 \mathrm{~m}$ distant. The sparse available rain-gauges in the basins are not adequate to provide this information, which is significant for identifying the prone area.

\section{CONCLUSION}

This paper has successfully presented the use of the high-resolution X-MP radar for rainfall estimation and prediction triggering the debris flow in Merapi volcanic region. The potential of extrapolation model to predict rainfall for very short-tem for further application in the real time scheme has been described. Performance of the model has been confirmed for very short-term with lead times of less than 1 hour in comparison with the observation. In most cases, forecasting with lead time longer than 2 hours consists high uncertainty. The advantage of radar for showing the spatially predominant rainfall in small scale for vulnerability assessment has been demonstrated considering rainfall threshold exceedance and terrain slope. The results indicate that Boyong River basin has high susceptibility of lahar flow compared with other three basins, which has been verified with past events and vulnerability map from authority. The real-time application and the development of vulnerability map based on historical data shows the potential of further X-MP radar utilization for deriving flood risk, despite it still has much room for improvement. The further study is suggested for evaluation of prediction model accuracy considering the uncertainty.

\section{ACKNOWLEDGEMENT}

The authors express sincere thanks to Satreps Project Kyoto University, Integrated Study on Mitigation of Multimodal Disasters caused by Ejection of Volcanic Products for supporting this study.

\section{REFERENCES}

[1] Lavigne F., Thouret J.C., "Lahars in Java: Initiations, Dynamics, Hazard Assessment And Deposition Processes", Forum Geografi, 21(1), (1988): 17-32.

[2] Lavigne, F., Thouret, Jean-Claude, "Sediment transportation and deposition by rain-triggered lahars at Merapi Volcano, Central Java, Indonesia”, Geomorphology, 49(1), (2003): 45-69.

[3] Segond, M.L., Wheater, H.S., Onof, C., "The significance of spatial representation for flood runoff estimation: A numerical evaluation based on the Lee catchment, UK”, Journal of Hydrology, 347, (2007): 116-131.

[4] Reyniers, M., "Quantitative precipitation forecasts based on radar observations”, Royal Meteorological Institute of Belgium, (2008).

[5] Shiiba, M., Takasao, T., Nakakita, E., "Investigation of short-term rainfall prediction method by a translation model", Japan Conference on Hydraulic Engineering, 28 ${ }^{\text {th }}$, (1984): 423-428.

[6] Westen, J. van and Daag, A. S., "Analysing the relation between rainfall characteristics and lahar activity at Mount Pinatubo, Philippines", Earth Surf. Process. Landforms, 30, (2005).

[7] Rodolfo, K.S. and Arguden, A.T., "Rain lahar generation and sediment delivery systems at Mayon Volcano Philippines", Sedimentation in Volcanic Settings - SEPM Special Publication, 45, (1985).

[8] Islam MM. and Sado K., "Development of flood hazard map of Bangladesh using NOAA-AVHRR images with GIS", Hydrological Sciences, 453(3), (2000): 337-401. 
[9] "Geophysical Mass Flow Group (GMFG)", TITAN2D User Guide. University at Buffalo, Buffalo NY, 1.030814 edition, (2004).

[10] Nakatani K., Satofuka Y., Mizuyama T., 'Development of 'KANAKO', a wide use debris flow simulator equipped with GUI", Proc. of 32nd Congress of IAHR, Venice, Italy, (2007).

[11] Niu, F., Luo, J., Lin, Z., Liu, M., Yin, G., "Thaw-induced slope failures and susceptibility mapping in permafrost regions of the Qinghai-Tibet Engineering Corridor, China", Bull Volcanol, 59, (1998): 460480.

[12] MLIT Japan, "Guidelines for development of warning and evacuation system against sediment disasters in developing countries", Ministry of Land, Infrastructure, Transport and Tourism, Japan, (2011).

[13] Maki, Masayuki, T. Maesaka, R. Misumi, K. Iwanami, S. Suzuki, A. Kato, S. Shimizu, "X-band polarimetric radar network in the Tokyo metropolitan area", In International Workshop on the Hazardous Winds Associated with Severe Storms, (2008).

[14] Fox, N.I., Wilson J.W., "Very short period quantitative precipitation forecasting", Atmospheric Science Letter, Vol. 6, (2005): 7-11. 
International Journal of Control and Automation Vol. 12, No. 8 (2019) 